ARTICLE

https://doi.org/10.1038/s41467-019-13616-1

\title{
Small molecules that inhibit TNF signalling by stabilising an asymmetric form of the trimer
}

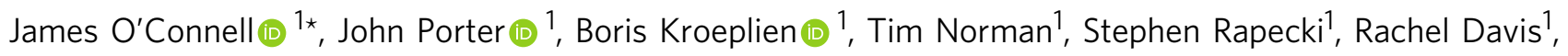
David McMillan (10 1, Tracy Arakaki², Alex Burgin ${ }^{3,5}$, David Fox III ${ }^{4}$, Tom Ceska1, Fabien Lecomte ${ }^{1}$, Alison Maloney ${ }^{1}$, Alex Vugler ${ }^{1}$, Bruce Carrington ${ }^{1}$, Benjamin P Cossins ${ }^{1}$, Tim Bourne ${ }^{1} \&$ Alastair Lawson ${ }^{1}$

Tumour necrosis factor (TNF) is a cytokine belonging to a family of trimeric proteins; it has been shown to be a key mediator in autoimmune diseases such as rheumatoid arthritis and Crohn's disease. While TNF is the target of several successful biologic drugs, attempts to design small molecule therapies directed to this cytokine have not led to approved products. Here we report the discovery of potent small molecule inhibitors of TNF that stabilise an asymmetrical form of the soluble TNF trimer, compromising signalling and inhibiting the functions of TNF in vitro and in vivo. This discovery paves the way for a class of small molecule drugs capable of modulating TNF function by stabilising a naturally sampled, receptor-incompetent conformation of TNF. Furthermore, this approach may prove to be a more general mechanism for inhibiting protein-protein interactions.

${ }^{1}$ UCB Pharma, Slough SL1 3WE, UK. ${ }^{2}$ Covance Inc, Princeton, NJ 08540, USA. ${ }^{3}$ Broad Institute of Harvard and MIT, Cambridge, MA 02142, USA. ${ }^{4}$ UCB Pharma, Bainbridge Island, WA 98110, USA. ${ }^{5}$ Present address: The Institute for Protein Innovation, 4 Blackfan Circle, Boston, MA 02115, USA.

*email: james.oconnell@ucb.com 
T NF antagonist treatments have been one of the success stories of recent years. Biologics such as infliximab, etanercept, adalimumab, golimumab and certolizumab pegol have proved efficacious in the clinic and have a well-documented mode of action and side-effect profile ${ }^{1}$. Nonetheless, the use of biologics remains restricted to a subset of the potential patient population, as immunogenicity ${ }^{2}$, supply chain complexity ${ }^{3}$ and health economics restrict their application. It is clear that many more patients could benefit from a small molecule drug with the efficacy of the anti-TNF biologics.

The compound SPD-304 targets TNF directly and has been shown to inhibit activity by destabilising the TNF trimer, resulting in a dimer that is no longer able to interact with receptor ${ }^{4}$. Although this strategy has so far not led to molecules capable of being developed, work is continuing in this area ${ }^{5-7}$. The TNF trimer may also be induced to disassemble by aggregating small molecules ${ }^{8}$. These, however, behave as promiscuous aggregators ${ }^{9}$ and the inhibition can be reversed with detergent, a hallmark of promiscuous aggregators. Approaches have also been described using natural products such as Japonicone $\mathrm{A}^{10}$, and others have targeted the receptor rather than the TNF ligand ${ }^{11,12}$. The status of small molecule inhibitors of TNF has been reviewed in a number of articles ${ }^{13,14}$.

Small molecule modifiers of protein-protein interactions are generally described as orthosteric or allosteric. The former compete directly with the two proteins for binding. There are a number of examples described in the literature ${ }^{15,16}$. The potency of TNF for TNF receptor 1 (TNFR1) is picomolar and despite the interest in the field generated by the success of the biologics, no orthosteric small molecule inhibitors have been described. We believe that disrupting the interaction allosterically ${ }^{17}$ through a region of TNF that is not in direct contact with its receptor may offer advantages that make this an attractive way to block its mechanism of action. In this paper, we describe the discovery and characterisation of a way in which antagonism of TNF signalling is achieved in such a manner with low-molecular-weight compounds. This finding has the potential to broaden the availability of the therapeutic benefits of TNF inhibition.

\section{Results}

Fragments bind directly to TNF with slow binding kinetics. We screened 2000 chemical fragments $(\mathrm{MW}<300 \mathrm{Da})$ using surface plasmon resonance (SPR) measurement on a Biacore 4000. The fragments were passed over the Biacore chip surface coated with immobilised TNF and screened at a concentration of $250 \mu \mathrm{M}$ to detect weak binders. This screen identified UCB-6786 (Fig. 1a) and an analogue UCB-6876, which bound to TNF displaying a concentration-dependent response curve and selectivity over the TNFR1 extracellular domain and control proteins (Fig. 1b).

We next measured the binding kinetics of UCB-6876 for TNF by SPR. Association rate constants $\left(\mathrm{k}_{\mathrm{a}}\right)$ for typical small molecules are limited by the rate of diffusion and are commonly higher than $10^{6} \mathrm{M}^{-1} \mathrm{~s}^{-1} 18$ but here the $\mathrm{k}_{\mathrm{a}}$ proved to be remarkably slow $\left(923 \mathrm{M}^{-1} \mathrm{~s}^{-1}\right)$. Conversely, the dissociation rate constant of this compound was also slow, particularly for a fragment $\left(k_{\mathrm{d}}\right.$ of $\left.0.02 \mathrm{~s}^{1}\right)$ resulting in a $K_{\mathrm{D}}\left(k_{\mathrm{d}} / k_{\mathrm{a}}\right)$ of $22 \mu \mathrm{M}$. The slow kinetic profile is unusual for molecules of this size and the resulting curve (Fig. 1c) did not have the square wave shape that is typical of fragment binding.

Crystal structure and interactions of the TNF: compound complex. Attempts were then made to obtain an X-ray co-crystal structure by soaking apo-TNF crystals with compound and conducting co-crystallisation trials, also in the presence of the compound. In the soaking studies the presence of UCB-6876, but
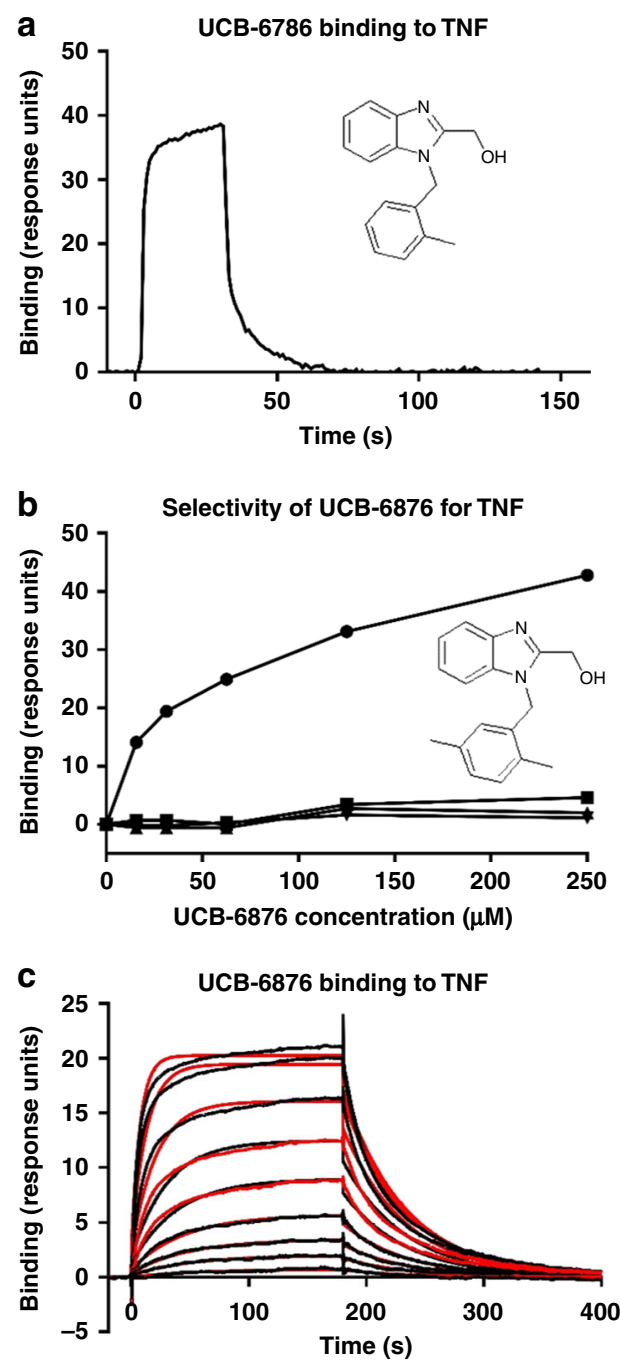

Fig. 1 Fragments bind to TNF with slow-binding kinetics. a SPR depicts the binding of UCB-6786 to immobilised TNF. $\mathbf{b}$ The analogue, UCB-6876, specifically binds to immobilised TNF (solid black circles) but not to control proteins, capture antibody plus TNFR1 (solid black squares), capture antibody (solid black triangle pointed down) or TNFR1 (solid black triangle pointed up). c Kinetic analysis of UCB-6876 using the Biacore T100 showing slow association and dissociation rates.

not a DMSO mock control, rapidly cracked and eventually dissolved the TNF crystals. In co-crystallisation trials, it prevented the crystallisation of TNF under our standard conditions. After screening for compound-dependent crystallisation conditions, crystals diffracting to $2.5 \AA$ were obtained for UCB-6876. The structure was solved by molecular replacement using individual monomers as a search model. The structure shows three TNF monomers in the asymmetric unit (ASU) (Fig. 2a) and clear electron density for one molecule of UCB-6876 bound at the centre of the TNF trimer (Fig. 2b). The fold of the individual TNF monomers was unchanged compared with apo-TNF (1TNF); however, their spatial arrangement had changed, resulting in a loss of the three-fold symmetry observed in all other published structures of TNF. The compound was buried within the space between the three TNF monomers and did not make any contact with solvent. The key interactions appeared to be the hydrogen bond from a benzimidazole $\mathrm{N}$ atom to $\mathrm{Y} 151^{\mathrm{C}}$ (Y151 in chain $\mathrm{C}$ ) and $\pi$ stacking of the benzimidazole with $\mathrm{Y}^{2}{ }^{\mathrm{C}}$. The 2,5-dimethylbenzyl moiety of UCB-6876 filled a hydrophobic pocket, assigned as Site 2, with compound TNF interactions composed of 
a
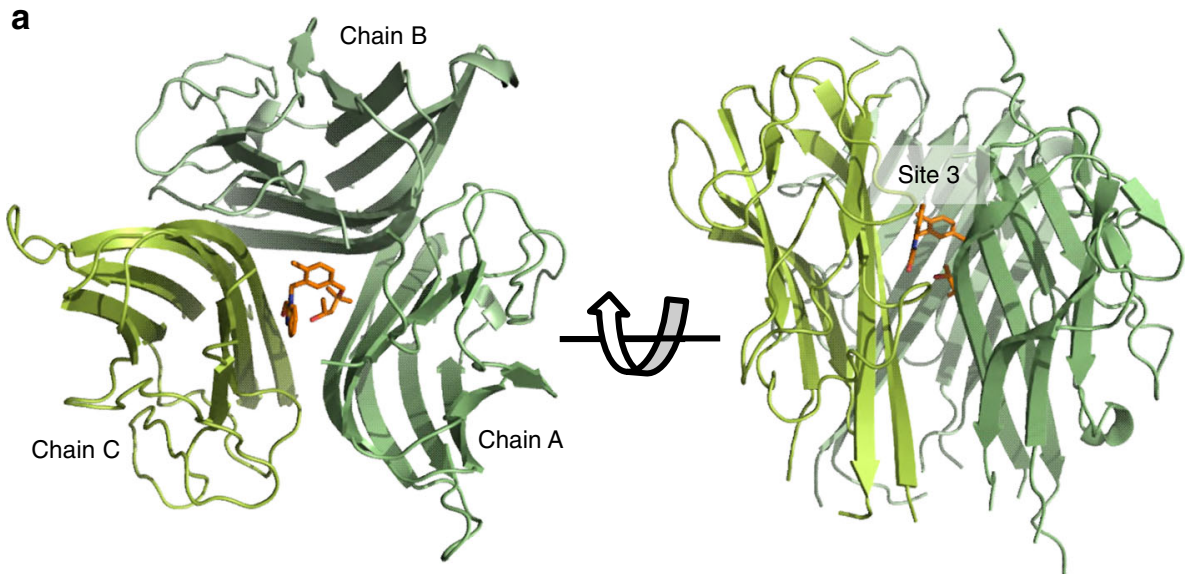

b

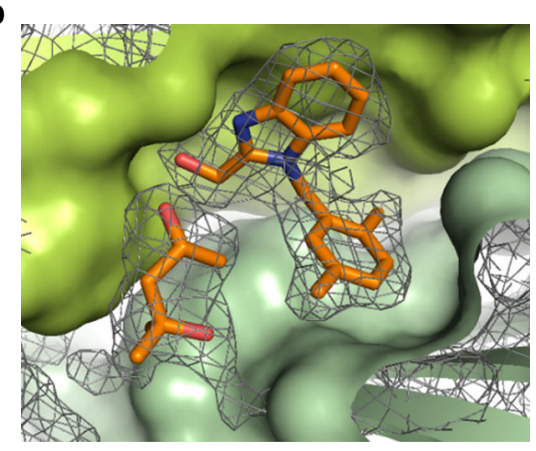

C

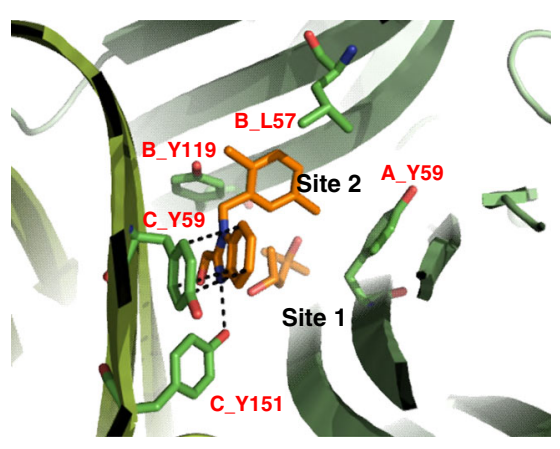

d
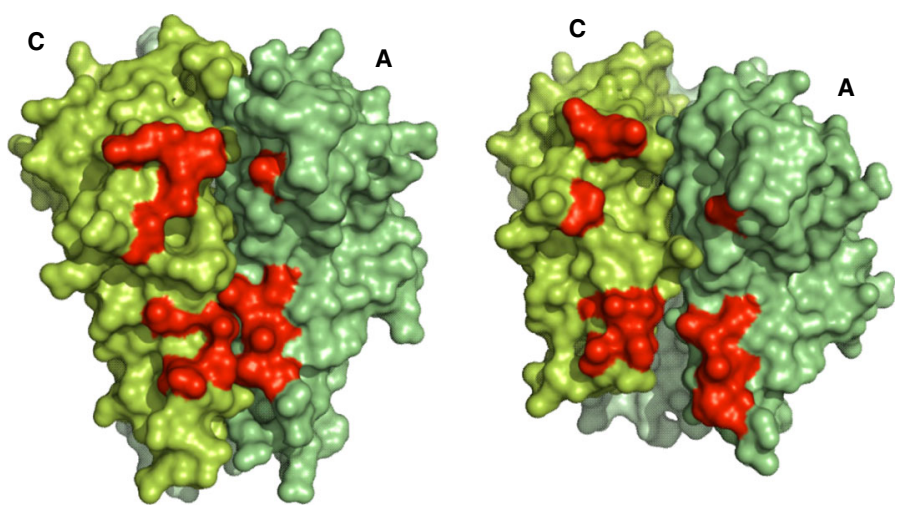

Fig. 2 Crystal structure of human TNF with UCB-6876. a Top and side views of TNF (green ribbons) with UCB-6876 bound (orange sticks). b Detail showing the electron density of UCB-6876 and MPD bound within the TNF homotrimer. Monomers B (light green) and C (green) are shown surface rendered. Contour level of the electron density is set at 1 sigma. MPD occupies a space next to UCB-6876. Subsequent molecules described in this paper were modified to have chemical groups occupying the space where MPD was bound. c Detail of the compound-binding pocket within the TNF homotrimer, with key residues involved in binding highlighted (sticks and labels). d Side view of apo-TNF (left image) and UCB-6876 bound TNF (right image) revealing the distorted AC receptor-binding site (selected residues involved in TNFR1 binding are highlighted red).

Y59 ${ }^{\mathrm{A}}$, Y $119^{\mathrm{B}}$ and $\mathrm{L} 57^{\mathrm{B}}$ (Fig. $2 \mathrm{c}$ ). It is also interesting to note that a single molecule of methylpentanediol (MPD), a co-crystallant required for crystal formation, was observed in an adjacent pocket designated as Site 1 (PDB: 6OOY).

The asymmetry of the compound-bound TNF trimer results in minor distortion at two of the receptor-binding sites and a more significant change at the AC binding site (i.e., the receptor-binding site formed at the interface of the arbitrarily assigned A and $\mathrm{C}$ monomers in the crystal lattice). There is a clear opening of the AC site because of monomer A twisting and tilting down and away from monomer C (Fig. 2d). By aligning compound-bound TNF with apoTNF (1TNF) through monomer $\mathrm{C}$, the degree of movement of selected residues involved in receptor binding on monomer $\mathrm{A}$ was measured, revealing shifts of between $5.6 \AA$ and $9.5 \AA$ (Supplementary Table 1 summarises the movement of selected residues and
Supplementary Movie 1 uses the crystal structures of apo-TNF and compound-bound TNF to show the overall change in TNF when compound is bound.) Stereo images of portions of the electron density maps can be found in Supplementary Fig. 1.

Stabilisation of TNF by small molecule binders. We were interested in the mechanism of action of these inhibitors and hypothesised that small molecules such as UCB-6876 are unlikely to induce a large quaternary conformational change as seen here. Also, the UCB compounds bind significantly faster than the timescale suggested for subunit exchange 4 . An enhanced molecular dynamics simulation ${ }^{19}$ was used to investigate the conformational transition between the symmetrical apo-TNF and the asymmetrical, open conformation of the TNF trimer 
a
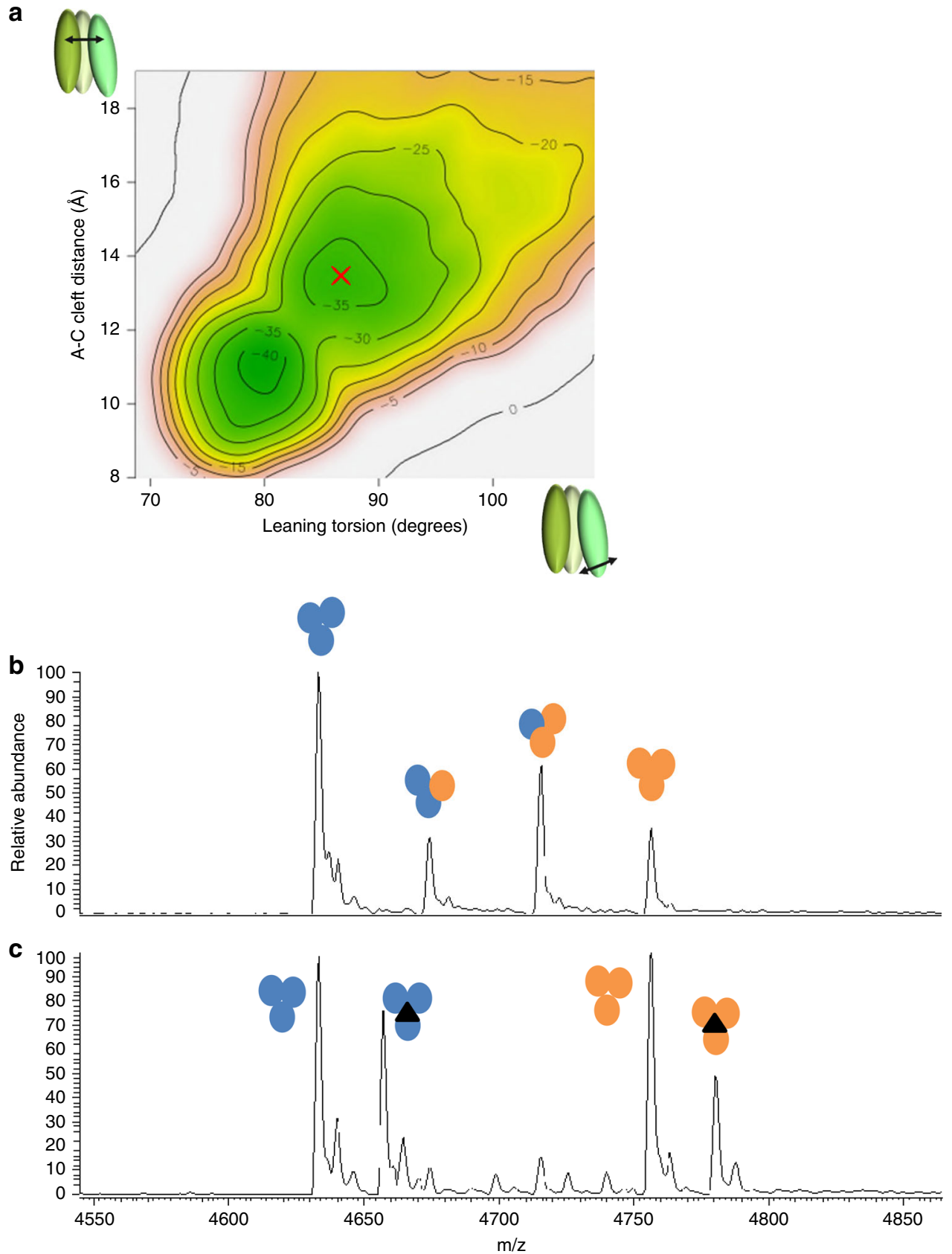

Fig. 3 TNF stabilisation by molecular dynamics and monomer exchange. a Meta-dynamics molecular dynamics simulation was used to produce this freeenergy surface. The simulation used a torsion describing the leaning angle of subunit $\mathrm{A}$ with respect to the other subunits and a distance describing how open the AC cleft is. b Mass spectrometry analysis of a mixture of human TNF (orange circles) and mouse TNF (blue circles) showing peaks corresponding to homotrimers and heterotrimers. c An equivalent analysis using human TNF pre-incubated with UCB-6876 (black triangle) showing that the compound blocks the exchange of mouse and human monomers.

(Supplementary Fig. 2). These simulations were carried out without the inclusion of our small molecule inhibitor in order to understand the stability of the unbound asymmetric open conformation. The free-energy surface (FES) generated by this dynamic model (Fig. 3a) shows two clear energy basins: the symmetrical trimer (at 80 degrees leaning torsion and $11 \AA$ cleft distance) and a stable asymmetric trimer (marked with a red cross). The shape of our FES suggests that the asymmetric open state would be stable without a bound inhibitor, as there is a significant free-energy barrier to returning to the symmetric closed conformation, which is calculated to be about $5 \mathrm{kcal} \mathrm{mol}^{-1}$ more stable. Hence, we expect that this new conformation of TNF is formed by conformational selection as suggested by Double Electron-Electron Resonance (DEER) analysis ${ }^{20}$ and stabilised by UCB-6876. This model supports our hypothesis that the compounds can bind to and stabilise a naturally sampled transient TNF trimer conformation. That UCB-6876 binds to a low abundance form of TNF is consistent with the slow on-rate observed by SPR, since the association rate constant is dependent on binding site access and concentration. As indicated by the crystal structure, once bound it is completely buried between the TNF monomers, explaining the slow dissociation rate.

We confirmed that the compounds stabilised the TNF trimer by investigating their effect on the process of TNF monomer 
exchange. At low physiological concentrations, the trimer can dissociate into monomers ${ }^{21}$, and these have been shown to exchange with monomers from a different TNF molecule 22,23 .

To test this by mass spectrometry, we used mouse TNF, which has a different molecular weight to human and has been shown to exchange monomers by Biacore ${ }^{22}$. We first showed that incubating a mixture of mouse and human TNF quickly produced heterotrimers consisting of different ratios of mouse monomer and human monomer (Fig. 3b). This suggests that the trimer can re-form by exchanging monomers and dimers between mouse and human TNF.

We then saturated human TNF with UCB-6876 and repeated the experiment. This time only intact human and mouse TNF homotrimers were observed, indicating that significant exchange of monomers between mouse and human TNF had not occurred (Fig. 3c and Supplementary Table 2).

Improving the affinity of compounds for TNF for in vitro and in vivo studies. To allow us to test for a functional effect in a cellbased assay we set out to improve the affinity of these compounds. Comparison of the co-crystal structure to the symmetrical apo-TNF structure showed that the ligand binding pocket was created by movement of $\mathrm{Y} 119^{\mathrm{C}}$ together with movement of the three TNF monomers relative to one another, creating space for the compound. We extended UCB-6876 to occupy the MPD binding pocket (termed Site 1 in Fig. $2 \mathrm{~b}$ ) to give the pyridyl analogue UCB-5307 (Supplementary Fig. 3), which showed a significant improvement in potency $\left(K_{\mathrm{D}}=9 \mathrm{nM}\right.$ and $k_{\mathrm{d}} 5.76 \mathrm{E}$ $-05 \mathrm{~s}^{-1}$; Supplementary Fig. 3 ) over UCB-6876. As expected, the co-crystal structure of UCB-5307 (PDB: 6OOZ) showed that the appended pyridyl group occupied the MPD pocket. The pyridyl nitrogen formed an $\mathrm{H}$-bond with $\mathrm{Y} 119^{\mathrm{A}}$, accounting for the increase in potency (Supplementary Fig. 4). The overall degree of TNF distortion had not changed, however, suggesting that the increased potency is simply due to an increased affinity, hence stabilisation. Indeed, the level of TNF stabilisation measured by thermal denaturation was significantly increased in the presence of UCB-5307 $\left(\Delta 11.8^{\circ} \mathrm{C}\right)$ compared with TNF in the presence of DMSO alone (Supplementary Table 3).

We then turned our attention to Site 3 , which extends towards the solvent channel. We determined that this would be accessible from the 5-position or 6-position of the benzimidazole. Addition of a pyrazole group at this position produced UCB-9260 (PDB: 6OP0) (Supplementary Fig. 5), which bound TNF with a similar $K_{\mathrm{D}}$ of $13 \mathrm{nM}$ but had a slower off-rate in the Biacore assay $\left(k_{\mathrm{d}}=\right.$ 4.39E-05 s ${ }^{-1}$; Supplementary Fig. 3), and resulted in further stabilisation of the TNF trimer $\left(\Delta 17.1^{\circ} \mathrm{C}\right.$ ) (Supplementary Table 3).

Consequence of TNF distortion on receptor binding. We were interested in the effect that distortion of the trimer would have on receptor binding and the consequence for signalling activity in cell and animal systems. We used analytical size exclusion (AnSEC) to test if asymmetric TNF was compromised in its ability to bind TNFR1.

To help interpret this, the migration profile of human TNF (hTNF) with one, two or three receptors bound was first characterised by titrating hTNFR1 with hTNF (Supplementary Fig. 6). To measure the effect of compound, hTNF trimer was incubated overnight with four concentrations of UCB-5307 prior to incubation with a 3.2-fold excess of receptor. The compound had little effect on the migration of hTNF alone (Fig. 4a, red and blue traces), and in the absence of compound, a single peak was observed corresponding to hTNF with three receptors bound (Fig. 4a, green trace). As compound concentration was increased, there was a dose-dependent shift from three receptors bound to two (Supplementary Fig. 7a). At the highest compound concentration (TNF fully occupied by UCB-5307) the major species was the two-receptor bound form (Fig. 4a, brown trace).

Preloading hTNF with UCB-5307 blocked one receptor from binding, so we next tested the ability of UCB-5307 to disrupt a preformed hTNF/hTNFR1 complex. Complex formed using a slight excess of receptor over TNF was challenged with the same range of compound concentrations, and the results indicate that UCB-5307 could penetrate the preformed complex, dislodging one of the receptors (Supplementary Fig. 7b). At the highest compound concentration, the degree of disruption was less pronounced compared with that seen when preloading the TNF with UCB-5307 (Fig. 4b, compare red and blue traces), and the ratio of two receptor-bound to three receptor-bound species was approximately equal (Fig. 4b, red trace).

TNF small molecule compounds inhibit TNFR1 signalling and downstream function in vitro. In order to assess the effect of the compounds in the TNFR1 signalling pathway, we first looked at events proximal to TNFR1 by measuring signalling protein recruitment to TNFR1, in particular RIP-1, which appears as a ubiquitinylated ladder on gels ${ }^{24}$. In addition, we evaluated the downstream signalling endpoint, phosphorylated NF- $\kappa B$ (pNF$\kappa B)$, which is distal to the TNF:TNFR1 signalling complex ${ }^{25}$. After TNF stimulation alone, increased levels of RIP were recruited to TNFR1, with a concomitant increase in phosphorylation of NF- $\kappa B$ (Fig. 5a, lane 2). However, when TNF was preincubated for $1 \mathrm{~h}$ with UCB-9260, recruitment of these proteins to the TNFR signalling complex, and subsequent phosphorylation of NF- $\kappa \mathrm{B}$, were markedly reduced to levels approaching those seen when TNF was pre-incubated with the TNF biologic, etanercept (Fig. 5a). This demonstrated that these compounds inhibited the ability of TNF-stimulated TNFR1 to recruit downstream proteins involved in signalling through NF- $\kappa \mathrm{B}$. We next determined the cell potency and selectivity of compounds in a high-throughput human cell-based reporter gene assay measuring the response of SEAP-linked NF- $\kappa \mathrm{B}$ to TNF (human or mouse) stimulation in the HEK 293 cell-line. In the same system, we were also able to test the selectivity to TNF by using an agonistic monoclonal antibody to TNFR $1(0.3 \mu \mathrm{g} / \mathrm{mL})$ to stimulate NF- $\kappa B$ via the same pathway (Supplementary Fig. 8). UCB-9260 inhibited NF- $\kappa$ B with a geometric mean $\mathrm{IC}_{50}$ of $202 \mathrm{nM}(95 \% \mathrm{CI}=53$, $n=8$ ) after TNF stimulation (Fig. 5b Supplementary Fig. 9b), but there was no inhibition of NF- $\mathrm{BB}$ stimulated by the TNFR1 agonist antibody. Since both TNF and the agonistic antibody signal via the same pathway this indicates that the effect of UCB9260 is through TNF in this system.

We then tested if the compounds could inhibit both human and mouse TNF-dependent functional activity by evaluating UCB-9260 using a mouse cell L929 TNF-dependent cytotoxicity assay, which had previously been used to characterise TNF biologics in vitro ${ }^{26}$. UCB-9260 inhibited TNF-dependent cytotoxicity with a geometric mean $\mathrm{IC}_{50}$ of $116 \mathrm{nM},(95 \% \mathrm{CI}=15$, $n=203)$ and a geometric mean $\mathrm{IC}_{50}$ of $120 \mathrm{nM},(95 \% \mathrm{CI}=16$, $n=180$ ) using human and mouse TNF, respectively (Fig. $5 \mathrm{c}$ and Supplementary Fig. 9b). These data showed that the compound inhibited the signalling and function of TNF and was suitable for testing in mouse in vivo models.

Mouse in vivo activity. Since UCB-9260 was to be used for in vivo studies, we first confirmed that there were no selectivity flags using the CEREP ExpresSProfile panel. We then tested the effect of this compound on other members of the TNF superfamily with trimeric structures similar at a superficial level at least 

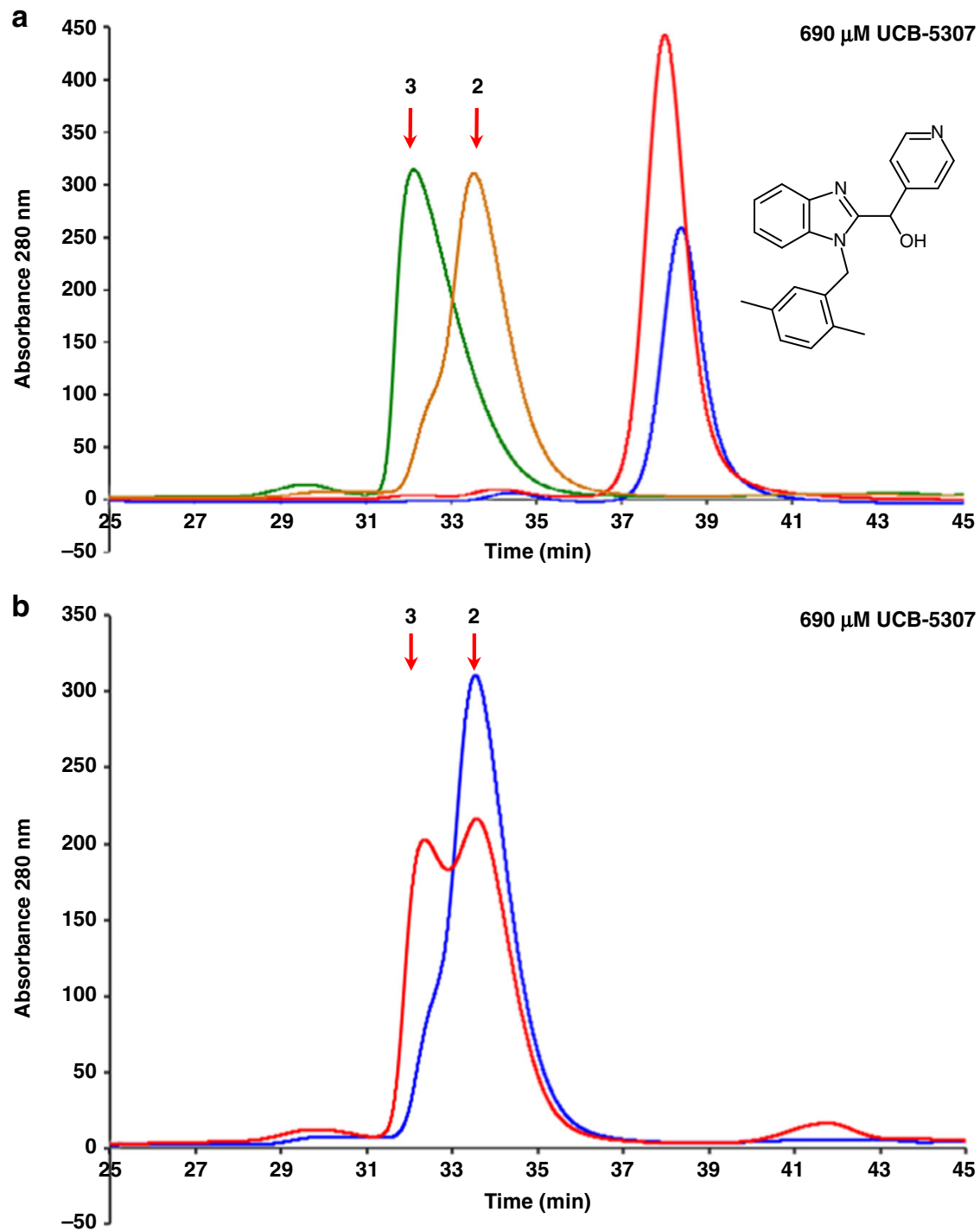

Fig. 4 Effect of compounds on TNF:TNFR1 stoichiometry. a Analytical size exclusion chromatography (AnSEC) of human (h) TNF alone (blue trace), hTNF + UCB-5307 (red trace), hTNF + 3.2-fold excess hTNFR1 (green trace) and hTNF + 3.2-fold excess hTNFR1 + 690 $\mu$ M UCB-5307 (brown trace). Expected migration position of hTNF with two and three receptors bound are indicated by arrows. Standard trace shown in Supplementary Fig. 5. b AnSEC comparing effect of $690 \mu \mathrm{M}$ UCB-5307 on preformed hTNF/hTNFR1 complex (3.2-fold excess hTNFR1) (red trace) vs. hTNF preloaded with UCB-5307 followed by addition of 3.2-fold excess hTNFR1 (blue trace) as in experiment (a). Source data are provided as a Source Data file.

to TNF. We used thermal melting to test the ability of UCB-9260 to stabilise other members of the TNF superfamily in the presence of DMSO compared with TNF (Supplementary Figs. 10,11). No other protein tested showed a significant change in Tm, suggesting that the action of UCB-9260 is specific to TNF.

We were also interested in trying to understand why these molecules were so selective for TNF over other family members. This was particularly surprising because some of the family members have similar residues to TNF at the binding site. We tested one possibility: that compounds could not access the binding site in the centre of the trimer of these proteins. We noted by comparing crystal structures that TNF had a leucine at position 57, whereas many of the other members of this family had a larger phenylalanine or tyrosine. This is close to the binding pocket, and in the symmetrical molecules these residues are close to one another (one from each chain) thus forming a 'gateway' to the pocket. Accordingly, we mutated Leu57 of TNF to phenylalanine, mimicking other family members, to which our compounds did not bind in a thermal melt assay. The mutated TNF (L57F) was equally active as wild-type TNF in a HEK assay
(Supplementary Fig. 9c), but the compounds showed no activity as demonstrated with UCB-9260 (Supplementary Fig. 9d).

Having confirmed that UCB-9260 was selective for TNF over other superfamily members, it was tested for activity in vivo using a TNF-dependent mouse model. One such model measures the ability of exogenous TNF injected into the mouse peritoneal cavity to induce neutrophil recruitment ${ }^{27}$. Either human or murine TNF can be tested because both signal through murine TNFR $1^{28}$. We performed a dose-response experiment with UCB9260 to assess its ability to inhibit both TNF stimuli, compared with a suitable anti-TNF biologic (CDP571) ${ }^{29}$ to inhibit human TNF, and etanercept to inhibit murine TNF. Following oral administration, UCB-9260 showed a dose-dependent inhibition of neutrophil recruitment, measured as $\mathrm{CD} 45^{+} \mathrm{GR} 1^{+}$cells by flow cytometry with significant inhibition obtained at $30 \mathrm{mg} / \mathrm{kg}$ of human TNF (Fig. 6a) and significant inhibition of murine TNF after a $10 \mathrm{mg} / \mathrm{kg}$ dose (Fig. $6 \mathrm{~b}$ and Supplementary Table 4). Additional supporting data using a zymosan-induced neutrophilia model can be found in Supplementary Fig. 12 and Supplementary Table 5. 
a
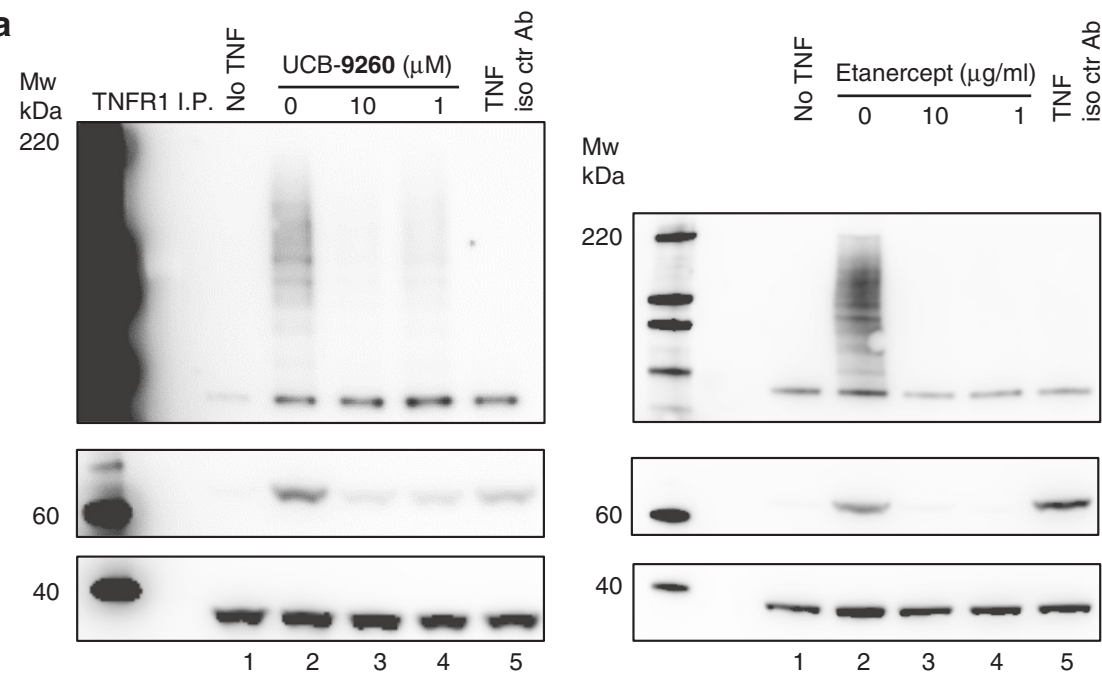

$\mathrm{Mw}$
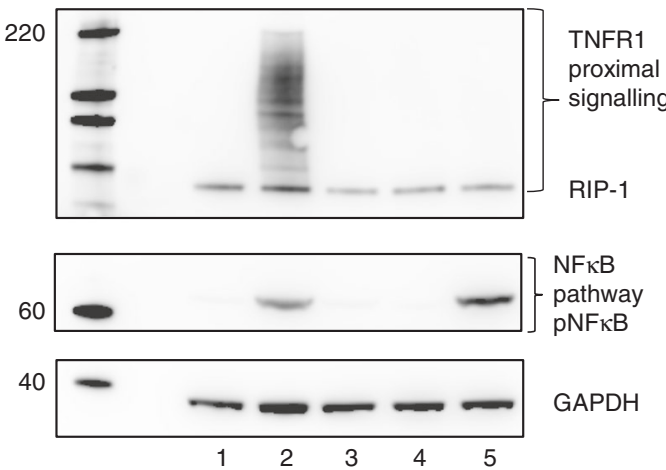

$\mathrm{NF \kappa B}$

pathway

pNFKB

b

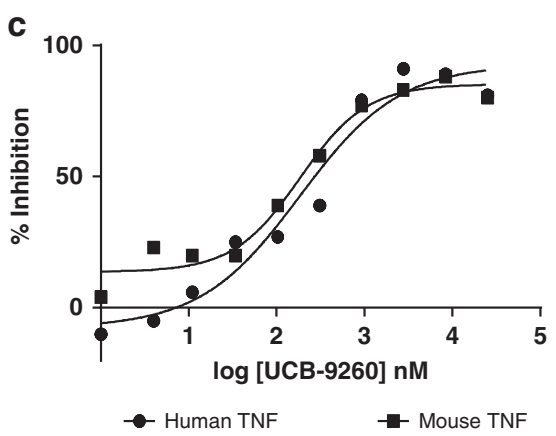

GAPDH

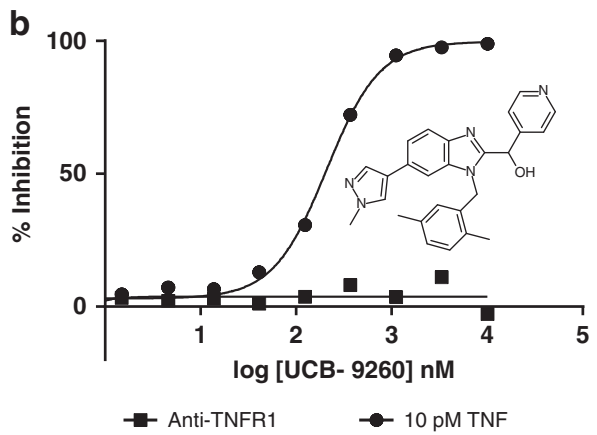

Fig. 5 Inhibition of TNF signalling in cells. a Western blots measuring RIP1 ubiquitination following TNFR1 immunoprecipitation from Jurkat cells treated with TNF \pm UCB-9260 or etanercept. pNFkB expression was assessed, along with GAPDH for loading control. An isotype control antibody was included as an immunoprecipitation control (lane 5). b TNF (10 pM) or anti-TNFR1 agonist antibody $(0.3 \mathrm{mg} / \mathrm{mL}$ )-driven NFkB activity was measured following UCB-9260 treatment in Hek-293 cells using a reporter gene assay system. Representative concentration-response curves are shown. Percentage inhibitions for compound dilutions were calculated between a DMSO control and maximum inhibition (by excess biologic anti-TNF, or NFkB inhibitor-TPCA-1). Untransformed data shown in Supplementary Fig. 10c. c UCB-9260 inhibition of TNF (human or mouse) dependent cytotoxicity was measured in mouse L929 cells. Representative concentration-response curves are shown. Percentage inhibition was calculated between unstimulated wells (maximum signal), and wells with TNF, DMSO and actinomycin D (minimum signal). Untransformed data shown in Supplementary Fig. 10d. Source data are provided as a Source Data file.

The collagen antibody induced arthritis (CAIA) model uses a combination of an anti-collagen antibody cocktail and lipopolysaccharide (LPS) to produce rheumatoid arthritis-like symptoms in the mouse $\mathrm{e}^{30}$. In this model, an in-house blocking murine antibody (Ab501) showed profound inhibition of the clinical score (Fig. 6c). UCB-9260, dosed orally at $150 \mathrm{mg} / \mathrm{kg}$ twice daily (bid), $6 \mathrm{~h}$ after the LPS challenge (therapeutic dosing), also showed a significant reduction of the clinical score (Fig. 6c). Statistically significant inhibition in these models was associated with unbound blood concentrations of compound that were maintained above the in vitro human and mouse TNF $\mathrm{IC}_{50}$ values (Supplementary Table 6).

\section{Discussion}

We have discovered orally active small molecules that inhibit TNF activity both in vitro and in vivo. The compounds bind to a pocket in the centre of the TNF trimer formed by the movement of the TNF monomers, stabilising the distorted trimer, which leads to reduced signalling through TNFR1. Analytical size exclusion suggests that the asymmetric trimer only binds to two receptors, consistent with the structural data showing significant distortion at one receptor binding interface. Rather than inducing a conformational change, we believe that the compounds bind to TNF through a process that is largely governed by conformational selection as suggested by our molecular dynamic (MD) simulations (Fig. 3a) and DEER experimental data. We show here an approach to inhibiting TNF through allosteric binding using small, drug-like, orally available molecules that we believe stabilise a naturally occurring conformer of TNF.

Inhibiting protein-protein interactions (PPIs) with small molecules has been described as reaching for the chigh hanging fruit $^{\prime 31}$. Indeed, the disruption of PPIs has been considered difficult by medicinal chemists for many years and there are few examples in the literature ${ }^{32}$. The surface between proteins is typically large, flat and featureless. Accordingly, many groups choose to target these interactions using relatively large molecules based on peptides or scaffolds that mimic peptides. Other approaches, however, have been described, such as targeting 'hot spots' in the binding site that appear to contribute most of the binding energy, making smaller molecules a viable alternative ${ }^{33}$. Notably, so-called fracturing of CD40L, a member of the TNF superfamily, using a relatively large molecule retained the trimeric assembly ${ }^{34}$. Indeed, there is some overlap between where this compound binds on CD40L and the TNF binders described here. Furthermore, stabilisation of protein complexes by binding naturally occurring small molecules at the interface has also been described $^{35}$, and it is interesting to speculate that there could be naturally occurring molecules that specifically modulate the function of TNF. Most importantly, this work suggests a method 
a

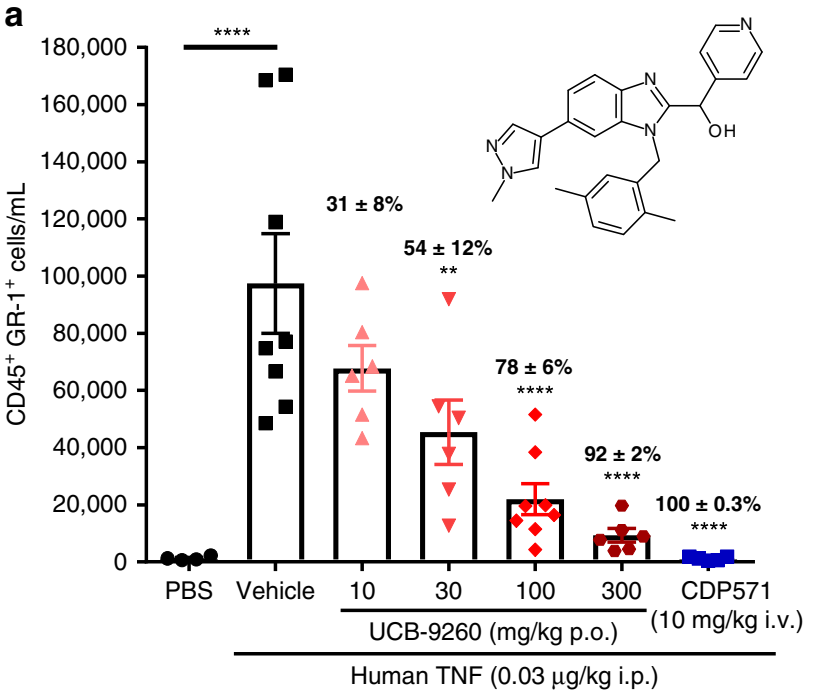

C

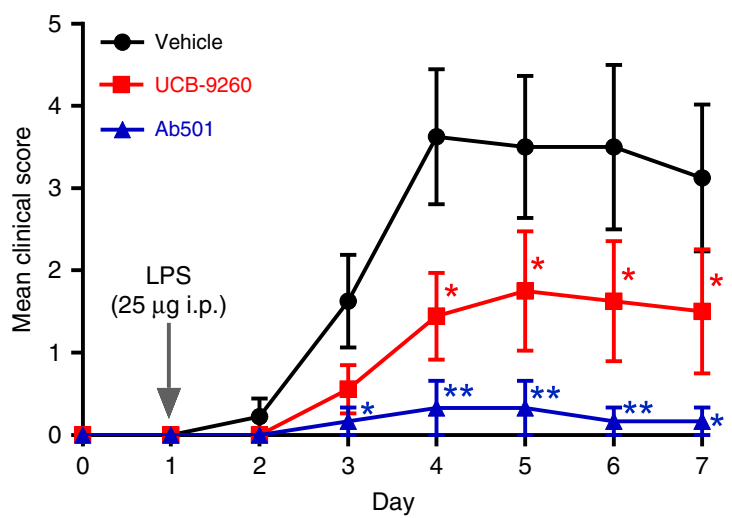

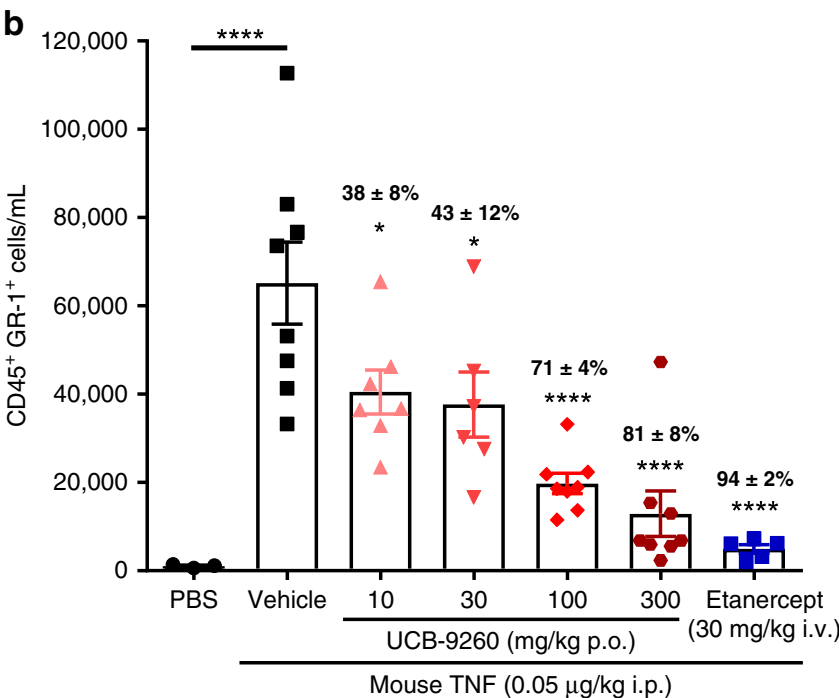

Mouse TNF $(0.05 \mu \mathrm{g} / \mathrm{kg}$ i.p.)

Fig. 6 Oral treatment with UCB-9260 inhibits TNF-driven functional effects in vivo. a UCB-9260 (10-300 mg/kg po, PBS $n=4$; vehicle $n=8$; UCB926010,30 and $300 \mathrm{mg} / \mathrm{kg} n=6$ and $100 \mathrm{mg} / \mathrm{kg} n=8 ;$ CDP571 $n=5$ mice) dose-dependently inhibits human and (b) mouse TNF-induced neutrophil recruitment to the peritoneal compartment in mice (PBS $n=3$; vehicle $n=8 ;$ UCB-9260 $10 \mathrm{mg} / \mathrm{kg} n=7,30 \mathrm{mg} / \mathrm{kg} n=6,100$ and $300 \mathrm{mg} / \mathrm{kg} n=8$; CDP571 $n=5$ mice). c UCB-9260 (150 mg/kg po bid) significantly reduces arthritis clinical score in the CAIA model (vehicle $n=8 ;$ UCB-9260 $n=8$ and AB501 $n=6$ mice). Mean data \pm standard error is shown. ${ }^{\star} p<0.05,{ }^{\star \star} p<0.01,{ }^{\star \star \star} p<0.001$ determined using one-way ANOVA with Dunnett's multiple comparison test. Exposure of UCB-9260 can be found in Supplementary Tables 4-6. Source data are provided as a Source Data file.

of discovering inhibitors using protein stabilisation of a nonactive conformation as an end point, which could be facilitated by an antibody that holds the target protein in the desired inactive conformation $^{36}$. Here we demonstrate that fragment-based drug discovery can be used to provide starting points for orally active compounds that modulate protein-protein interactions.

Small molecules offer several advantages over biologics, including cost, the convenience of oral delivery and shorter halflives, which benefit patients requiring drug holidays. In addition, they can be designed to diffuse across the blood-brain barrier, making them suitable for targeting central nervous system disorders. The possibility of being able to target TNF-driven neuroinflammation, for example, is particularly interesting.

From our experience with TNF, it seems that orally available, bona fide small molecules, capable of stabilising favoured, naturally sampled conformations of target proteins, offer an attractive and chemically tractable approach to tackling protein-protein interactions.

\section{Methods}

Biacore binding assay. BIA (Biomolecular Interaction Analysis) uses SPR to measure the binding of compounds to a protein immobilised on a chip surface. For this purpose a Biacore A100/4000 (GE Healthcare) was used. A CM5 sensor was immobilised via amine coupling on flow cell 1 with human $\mathrm{Fc}$ antibody domain (10k response units; $\mathrm{kRU}$ ) and TNFR-Fc captured ( $2.5 \mathrm{kRU})$, flow cell $2 \mathrm{TNF}$ (11 kRU), flow cell 3 was left blank (for non-specific binding), flow cell 4 TNFR-Fc (10 kRU), and flow cell 5 goat anti-human Fc $16 \mathrm{kRU}$ ). The sensor surface was then equilibrated in HBS-P (10 mM HEPES pH 7.4, $0.15 \mathrm{M} \mathrm{NaCl}$, 0.005\% Surfactant P20, BIAcore, GE Healthcare) with 5\% DMSO for at least $5 \mathrm{~h}$. Compounds were diluted from $100 \mathrm{mM}$ stocks into DMSO matched buffer and then flowed over the immobilised flow cells at a concentration of $250 \mu \mathrm{M}$ at the maximum flow rate of $30 \mu \mathrm{L} / \mathrm{min}$. Background subtraction binding curves were analysed using the Biacore A100 BIA evaluation software version 1.1 following standard procedures.

Biacore kinetics of binding. Surface plasmon resonance using a Biacore T100/ T200 was used to measure the association rate constant $(\mathrm{ka})$, the dissociation rate constant $(\mathrm{kd})$ and the affinity $\left(\mathrm{K}_{\mathrm{D}}\right)$ of compounds. TNF (VCID 2043 Beryllium) was immobilised to approximately $5 \mathrm{kRU}$ as described above and equilibrated for at least $5 \mathrm{~h}$ in HBS P + buffer with 5\% DMSO. UCB-6876 was serially diluted from $187.5 \mu \mathrm{M}$, flowing over the immobilised TNF at $50 \mu \mathrm{L} / \mathrm{min}$ for $3 \mathrm{~min}$ before allowing full dissociation under flow for at least $6 \mathrm{~min}$. Kinetic constants were obtained from multicycle data that had been double-referenced, the data fitted and then analysed using the Levenberg Marquardt algorithm in the BIA Evaluation software (Biacore T100 BIA evaluation version 1.1). Compounds UCB-5307 and UCB-9260 were titrated from $30 \mu \mathrm{M}$ with three-fold serial dilutions to $0.37 \mu \mathrm{M}$ and flowed over approximately $1.5 \mathrm{kRU}$ of linked TNF with an n-terminal HKH tag (Beryllium) in HBS P buffer with 5\% DMSO at $100 \mu \mathrm{l} / \mathrm{min}$. The compounds were allowed to dissociate for $2 \mathrm{~h}$ under flow. Kinetic constants from single-cycle data were obtained (Biacore T100 BIA evaluation version 1.1) and compound characterisation details can be found in Supplementary Notes 1-4. 
Crystallography: plasmid construction. Human TNF (CID2043, UniProt P01375 residues 77-233 [full plasmid sequences available in the source data file]) was codon-engineered in-silico using GeneComposer ${ }^{\mathrm{mot}}$ for E. coli expression, and optimised to balance GC content, exclude cryptic Shine Dalgarno sequences, as well as exclude BamHI and HindIII restriction sites. The final gene insert was flanked with 5' GGATCC (BamHI) and 3' TGATAAGCTT (HindIII is underlined), such that two stop codons follow the C-terminal residue. The final gene insert was then synthesised by DNA 2.0 and delivered in a shuttle vector. Following synthesis, the gene insert was digested with BamHI and HindIII and subcloned to vector pEMB54, which is an ampicillin-resistant, arabinose-inducible vector with pMB1 origin of replication and $6 \mathrm{XHis}-\mathrm{Smt} 3$ under the PBAD promoter, followed by a multiple-cloning site which includes BamHI followed by HindIII. After BamHI/HindIII cloning into pEMB54, gene inserts are fused in-frame with the 6XHis-Smt3 sequence. Following digestion of both pEMB54 and CID2043 inserts with BamHI/HindIII, both were gel-purified, the inserts ligated into the vector and the ligation transformed to chemically competent TOP 10 cells. One transformant was mini-prepped and submitted for DNA sequencing of the Open Reading Frame. CID7210 (see source data for plasmid sequence) was cloned in a manner similar to CID2043, and consisted of a triple tandem fusion of the TNF ECD ('TNF Trimer'), wherein Uniprot P01375 77-233 was followed by 85-233, with an SG linker between the TNF monomers. This gene (identical to CID3747) was optimised in GeneComposer with identical BamHI/HindIII adaptors, synthesised by DNA 2.0 and subcloned into final expression vector pEMB116, which is the same as pEMB54 except the N-terminal tag is HKH instead of 6XHis-Smt3. CID8703 was cloned via Quikchange mutagenesis (Agilent) using standard protocols, using CID2043 as a template.

Crystallography: protein expression and purification. Briefly, the target-specific vector was transformed into TOP10 E. coli cells. A starter culture containing $100 \mu \mathrm{g} / \mathrm{mL}$ (final concentration) ampicillin (Teknova) was inoculated with a single colony and grown for $16 \mathrm{~h}$ at $37^{\circ} \mathrm{C}$. This was then transferred to $8 \mathrm{~L}$ of Terrific Broth (Teknova) containing $100 \mu \mathrm{g} / \mathrm{mL}$ (final concentration) ampicillin and grown to $\mathrm{OD} 600=0.6$. Protein expression was induced by adding arabinose to a final concentration of $0.1 \%$ (VWR) and grown for $16 \mathrm{~h}$ at $25^{\circ} \mathrm{C}$. The cells were harvested by centrifugation (Beckman) at $6240 \times \mathrm{g}$ for $15 \mathrm{~min}$ and the pellets were collected and stored at $-80^{\circ} \mathrm{C}$.

Cells were resuspended $1 \mathrm{~g}: 4 \mathrm{~mL}$ in $25 \mathrm{mM}$ Tris(hydroxymethyl)aminomethane hydrochloride (Tris-HCl) pH 8.0 (Teknova), $200 \mathrm{mM} \mathrm{NaCl}$ (Teknova), $0.02 \% 3-$ [(3-Cholamidopropyl)dimethylammonio]-1-propanesulfonate (CHAPS) (JT Baker), $50 \mathrm{mM}$ L-arginine (Sigma), 500U of benzonase (Novagen), $100 \mathrm{mg}$ lysozyme (Sigma) and one complete EDTA-free protease inhibitor tablet (Roche). The cells were lysed via sonication (Misonix) and clarified via centrifugation at $142,000 \times g$ for $30 \mathrm{~min}$ at $4{ }^{\circ} \mathrm{C}$ (Beckman) and filtered with a $0.2 \mu \mathrm{m}$ bottle-top filter (Nalgene). The supernatant was applied to two $5 \mathrm{~mL} \mathrm{Ni}^{2+}$ charged HiTrap Chelating HP (GE Healthcare) columns and the protein eluted with a $500 \mathrm{mM}$ imidazole gradient over 20 column volumes. The fractions of interest were pooled and the His-Smt tag was removed via cleavage with Ubiquitin-like-specific protease 1 (Ulp-1) while dialysing against $2 \mathrm{~L}$ of $25 \mathrm{mM}$ Tris $\mathrm{pH} 8.0$ and $200 \mathrm{mM} \mathrm{NaCl}$ overnight at $4{ }^{\circ} \mathrm{C}$ using $3.5 \mathrm{kDa}$ MWCO snakeskin dialysis tubing. The affinity tag was removed by applying the digested pool over two $5 \mathrm{~mL} \mathrm{Ni} 2+$ charged HiTrap Chelating HP columns. The flow-through contained the cleaved protein of interest. The protein was concentrated for size exclusion chromatography via centrifugal concentration (Vivaspin Polyethylsulfone, $10 \mathrm{kDa}$ MWCO, Sartorius) to $13.5 \mathrm{mg} /$ $\mathrm{mL}$ for injection over a HiPrep 16/60 Sephacryl S-100 HR (GE Healthcare) in $10 \mathrm{mM}$ HEPES (2-[4-(2-hydroxyethyl)piperazin-1-yl]ethanesulfonic acid), $\mathrm{pH} 7.5$ and $150 \mathrm{mM} \mathrm{NaCl}$. Fractions of interest were pooled and concentrated via centrifugal concentration (Vivaspin Polyethylsulfone, $10 \mathrm{kDa}$ MWCO, Sartorius) to $20 \mathrm{mg} / \mathrm{mL}$, aliquoted and stored at $-80^{\circ} \mathrm{C}$.

Crystallography: crystallisation. Purified human TNF was diluted to $4-7 \mathrm{mg} / \mathrm{mL}$ in $10 \mathrm{mM}$ HEPES pH 7.5,150 mM NaCl buffer followed by overnight incubation at $4^{\circ} \mathrm{C}$ with $0.5 \mathrm{mM}$ compound (1-2 molar excess). The TNF-compound complex was crystallised by sitting drop vapour diffusion by mixing $0.5 \mu \mathrm{L}$ of complex with $0.5 \mu \mathrm{L}$ of 13\% MPD, 13\% PEG 1000, 13\% PEG3350, 0.1 M HEPES, pH 8.0. Crystals were harvested for data collection $\sim 2$ weeks after initial set-up. Crystals were cryoprotected in ethylene glycol and/or vitrified directly in liquid nitrogen for data collection.

\section{Crystallography: structure determination. The dataset for human TNF com-} plexed with UCB-6876 and UCB-9260 were collected at the Stanford Synchrotron Radiation Lightsource (SSRL) beam line 7-1 (ADSC Quantum-315R CCD X-ray detector). The dataset for human TNF complexed with UCB-5307 was collected at the Advanced Light Source (ALS) beam line 5.0.3 (ADSC Quantum-315R CCD Xray detector). Diffraction data were reduced and scaled with XDS/XSCALE ${ }^{37}$. The structure was solved by molecular replacement using Phaser with input model of 1TNF. Iterative manual model building using Coot (Emsley and Cowtan, 2004) $)^{38}$ and Refmac (Murshudov et al., 1997) ${ }^{39}$ continued until R and Rfree converged. Model quality was validated using Coot and MolProbity ${ }^{40}$. Structures were validated using Molprobity prior to deposition in the Protein Data Bank (PDB: 6OOY,
PDB: 6OOZ, PDB: 6OP0) $)^{41,42}$. Statistics for each crystal structure are provided in Supplementary Table 7.

Mass spectrometry monomer exchange. Mouse and human TNF protein were made up to a concentration of $2 \mathrm{mg} / \mathrm{mL}$ ( $20 \mathrm{mM}$ ammonium acetate, $\mathrm{pH} 7.4)$ and desalted and buffer-exchanged using Zeba columns. The protein was then diluted to $20 \mu \mathrm{M}$ in ammonium acetate buffer. An aliquot of each was mixed 1:1 and analysed at various time points. Human TNF was incubated (1:1, v/v) with compound $(20 \mu \mathrm{M}), 4 \%$ DMSO in $20 \mathrm{mM}$ ammonium acetate) and mixed with mouse TNF (1:1) and tested at various time points using an Advion Nanomate (for sample introduction by nanospray) and ThermoFisher Exactive Plus EMR Mass Spectrometer. The following settings were utilised on the mass spectrometer: scan range 1000 to $8000 \mathrm{~m} / z$; spray voltage $1.5 \mathrm{kV}$; capillary temperature $150^{\circ} \mathrm{C}$; S-lens $\mathrm{RF}$ 200 ; source DC offset $25 \mathrm{~V}$, injection flatapole $7 \mathrm{~V}$; inter flatapole $6 \mathrm{~V}$; bent flatapole DC 6 V; EMR mode on. Data were processed using ThermoFisher Protein Deconvolution 3.0.

Molecular dynamics simulation. Missing backbone atoms were added using FREAD ${ }^{43}$ database structure prediction software. An error in the amino acid sequence of TNF structure 1TNF was detected within this process. In all three monomers of PDB structure 1TNF residue 143 is a leucine; this is in contrast to sequence data for TNF stored in Uniprot ${ }^{44}$ where this residue is an aspartate. For this study residue 143 of 1TNF was mutated to an ASP. Maestro ${ }^{45}$ was then used to add all other missing atoms and pick sensible protonation states for titratable residues, ensuring that all homotrimers remained symmetric.

The ff $99 \mathrm{SB}^{45}$ Amber force field was employed for all protein parameters, set up using the LEaP software from AmberTools $1.4^{46}$. The TIP $3 \mathrm{P}^{47}$ water model was used in a solvating cube along with neutralising sodium chloride ions at an approximate concentration of $0.15 \mathrm{M}$. NAMD $2.7^{48}$ was used to carefully equilibrate for temperature and pressure $(300 \mathrm{~K}, 1 \mathrm{~atm})$. ACEMD ${ }^{49}$ was then used for a $1 \mathrm{~ns}$ structural equilibration and when patched with Plumed $1.3^{50}$, for all metadynamics simulations. ACEMD simulations used a 4 fs time step throughout. All simulations used particle mesh Ewald ${ }^{51}$ for long-range electrostatics with appropriate potential truncation and smoothing.

Initial metadynamics simulations used two CVs based on a quaternary torsion and a distance (Supplementary Fig. 1c, d). Gaussians were added every 1 ps with an initial height of $0.1 \mathrm{kcal} \mathrm{mol}^{-1}$. The bias-factor was set to 15 . Gaussian widths were set on a system basis using the last $200 \mathrm{ps}$ of a $500 \mathrm{ps}$ test run to estimate average fluctuation seen in 1 ps for each CV. A Gaussian width was chosen to be less than half of the average 1 ps fluctuation. Potential walls were employed to stop the opening subunits from dissociating. In these cases the inversion conditions of Crespo et al. were used to limit any error in the $\mathrm{FES}^{52}$. Wall and inversion parameters were chosen in line with the Gaussian widths being used. Convergence was pre-defined as a Gaussian height $<100$ times smaller than the initial value, convergence of any FE difference between open and closed states and free movement across any energy barriers. Hence, once a significant low energy region is found away from the apo (symmetric homotrimer state) region, a return to the apo region was deemed necessary.

PCA analyses of initial metadynamics simulations were carried out using the GROMACS ${ }^{53}$ programmes g_colvar and g_anaeig. The most important eigenvectors were chosen using the relative size of their eigenvalues.

Thermal denaturation assay of thermal stability. A fluorescence probed thermal denaturation assay was performed to assess the effect of the compounds on the thermal stability of TNF (or other members of the TNF family) as a measure of compound binding. The reaction mixture contained $5 \mu \mathrm{L}$ of $30 \times$ SYPRO $^{\oplus}$ Orange dye (Invitrogen) and $5 \mu \mathrm{L}$ of TNF (at $1 \mathrm{mg} / \mathrm{mL}$ ), $37.5 \mu \mathrm{L}$ PBS, pH 7.4 and $2.5 \mu \mathrm{L}$ of compound (at $2 \mathrm{mM}$ in DMSO). The mixture $(10 \mu \mathrm{L})$ was dispensed in quadruplicate into a 384 PCR optical well plate and was run on a 7900HT Fast RealTime PCR System (Agilent Technologies). The PCR System heating device was set at $20^{\circ} \mathrm{C}$ to $99^{\circ} \mathrm{C}$ with a ramp rate of $1.1^{\circ} \mathrm{C} \mathrm{min}{ }^{-1}$; fluorescence changes in the wells were monitored by a CCD device. The fluorescence intensity increase was plotted as a function of temperature and the $T_{\mathrm{m}}$ calculated as the midpoint of this denaturation curve (determined as the point of inflection).

Analytical size exclusion chromatography. A stock of compound bound to human (h) TNF was prepared by pre-incubating hTNF ( $300 \mu \mathrm{M}$, molecular weight based on the homotrimer) overnight at $4{ }^{\circ} \mathrm{C}$ with UCB-5307 at a final concentration range from $90 \mu \mathrm{M}$ to $690 \mu \mathrm{M}$, maintaining a constant DMSO concentration of $1 \%$. The compound-bound hTNF was incubated for $1 \mathrm{~h}$ at $22^{\circ} \mathrm{C}$ with hTNFR1 at a 3.2-fold molar excess over homotrimers (final concentrations: hTNFR1 $240 \mu \mathrm{M}$, hTNF $75 \mu \mathrm{M}$ ). Identical samples were prepared with DMSO only, giving a final DMSO concentration of $0.25 \%$ for both sets of samples. Alternatively, a fully assembled hTNF/hTNFR1 complex ( 3 receptors per homotrimer) was formed by incubating hTNF with a 3.2-fold molar excess of hTNFR1 for $1 \mathrm{~h}$ at $22^{\circ} \mathrm{C}$. The TNF/TNFR1 complex was then incubated overnight at $4{ }^{\circ} \mathrm{C}$ with UCB-5307 at a final concentration range from $90 \mu \mathrm{M}$ to $690 \mu \mathrm{M}$. Samples were subject to analytical size exclusion using HPLC. Injection volumes of $50 \mu \mathrm{L}$ 
were separated on a TSK G3000SW L $\times$ I.D. $30 \mathrm{~cm} \times 7.5 \mathrm{~mm}$ column $(10 \mu \mathrm{m}$ particle size) pre-equilibrated in $10 \mathrm{mM}$ HEPES, pH 7.5, $150 \mathrm{mM} \mathrm{NaCl}$.

TNFR1 immunoprecipitation and signalling assay. TNF $(25 \mathrm{ng} / \mathrm{mL})$ was preincubated with UCB-9260 $(10 \mu \mathrm{M})$ or anti-TNF $(20 \mu \mathrm{g} / \mathrm{mL}$, Etanercept, GlobalRx $)$ for $1 \mathrm{~h}$ at $37^{\circ} \mathrm{C}$, and then incubated for $5 \mathrm{~min}$ at $37^{\circ} \mathrm{C}$ with $50 \times 10^{6}$ Jurkat cells. Cells were then lysed for $1 \mathrm{~h}$ in cold lysis buffer ( $1 \% \mathrm{NP}-40,150 \mathrm{mM} \mathrm{NaCl}, 50 \mathrm{mM}$ Tris $\mathrm{pH} 8.0,25 \mathrm{mM} \mathrm{NaF}, 1 \mathrm{mM}$ vanadate, $1 \%$ phosphatase inhibitor and $0.2 \%$ protease inhibitor cocktail), and cell supernatant harvested. TNFR1 immunoprecipitation was performed by incubating supernatant with $5 \mu \mathrm{g}$ anti-TNFR1 antibody ( $\mathrm{R} \& \mathrm{D}$ systems, \#AB-225-PB) overnight while rotating at $4{ }^{\circ} \mathrm{C}$, followed by the addition of $20 \mu \mathrm{L}$ protein $\mathrm{G}$ sepharose beads for $1 \mathrm{~h}$ rotating at $4{ }^{\circ} \mathrm{C}$. An isotype control sample was incubated with $5 \mu \mathrm{g}$ goat IgG, instead of anti-TNFR1 antibody to assess how much unspecific binding to the beads occurs during immunoprecipitation. Beads were subsequently washed $3 \times$ in lysis buffer, and then the supernatant removed and SDS-PAGE reducing sample buffer added to beads and samples boiled for $10 \mathrm{~min}$. Sample $(15 \mu \mathrm{L})$ was then loaded on a $4-12 \%$ Bis-Tris gel and run for $65 \mathrm{~min}$ at $200 \mathrm{~V}$ in MOPS buffer. Gels were then transferred to nitrocellulose membrane using iBlot (Invitrogen) and blocked in 5\% milk in TBS/ $0.05 \%$ Tween (blocking buffer) for $1 \mathrm{~h}$. RIP-1 ubiquitination (1:250 dilution, BD, \#610459) was then detected by Western blotting using anti-mouse-HRP (1:2000 dilution, Cell Signalling Technology, \#7076). pNFkB (1:1000 dilution, Cell Signalling Technology, \#3033) and GAPDH (1:4000 dilution, Cell Signalling Technology, \#5174) were measured in the total cell lysates by Western blotting using anti-rabbit HRP (1:2000 dilution, Cell Signalling Technology, \#7074). Blots were developed by detecting chemiluminescence using ImageQuant (GE Healthcare).

TNF reporter gene assay using a HEK Blue Media ${ }^{T M}$ readout. Stimulation of HEK-293 cells by TNF leads to activation of the NF-kB pathway. The HEK-Blue ${ }^{\mathrm{TM}}$ CD40L SEAP (secreted embryonic alkaline phosphatase) reporter cell line used to determine TNF activity (InvivoGen, \#hkb-CD40, cells were described as mycoplasma free when purchased and were tested using Mycoalert [Lonza] after each batch of assay vial preparation). Compounds were titrated in DMSO and preincubated with TNF at a concentration giving half maximal response (10 pM for human or $20 \mathrm{pM}$ for mouse) or the anti-human TNFR1 agonist antibody (R\&D Systems. \#AF 225) for $1 \mathrm{~h}$. Cells were added to the compound/stimulus mixture and further incubated for $18 \mathrm{~h}$. SEAP was measured using the colorimetric substrate HEK-Blue Detect ${ }^{\mathrm{TM}}$ or QUANTI-Blue ${ }^{\mathrm{TM}}$ from InvivoGen. Percentage inhibitions for compound dilutions were calculated between a DMSO control and maximum inhibition (by excess anti-TNF biologic, or NF-kB inhibitor-TPCA-1 [Tocris \#2559, R\&D Systems]). The $\mathrm{IC}_{50}$ was determined as the point of inflexion between the fitted minimum and maximum of the compound dose response curve, calculated using $4 \mathrm{PL}$ fitted curve. Mean $\mathrm{IC}_{50} \mathrm{~s}$ are reported as a mean of at least two experiments. Dose response curves for TNF and the anti-human TNFR1 agonist antibody are shown in Supplementary Fig. 9.

TNF 1929 cytotoxicity assay. TNF (human or mouse) kills L929 cells which have been compromised by incubation with a sub-lethal concentration of actinomycin $\mathrm{D}$, and this effect is inhibited with TNF biologics ${ }^{18}$. Compounds were titrated in DMSO, and then pre-incubated with human or mouse TNF for $1 \mathrm{~h}$. L929 cells (ECACC, \#85011425) in media containing actinomycin D $(2 \mu \mathrm{g} / \mathrm{mL})$ were added to the TNF inhibitor mixture and incubated for $18 \mathrm{~h}$. L929 cytotoxicity was measured by the addition of CellTitreGlo (Promega). Luminescence was measured after an incubation of at least $20 \mathrm{~min}$ in the dark. Percentage inhibition was calculated between unstimulated wells (maximum signal), and wells with TNF, DMSO and actinomycin $\mathrm{D}$ (minimum signal). The $\mathrm{IC}_{50}$ was calculated as the point of inflexion for a $4 \mathrm{PL}$ fitted curve. Mean $\mathrm{IC}_{50} \mathrm{~s}$ are reported as a mean of at least two experiments. Cells were described as mycoplasma-free when purchased and were tested using Mycoalert (Lonza) after each batch of assay vial preparation.

\section{Mouse or human TNF induced neutrophil recruitment in vivo. All in vivo} studies were reviewed by an internal Ethical Review Body (ERB) and conducted in accordance with the Animals (Scientific Procedures) Act 1986, EU Directive 2010/ 63/EU. Adult male Balb/c mice (aged 6-8 weeks, human: PBS $n=4$; vehicle $n=8$; UCB-9260 10, 30 and $300 \mathrm{mg} / \mathrm{kg} n=6$ and $100 \mathrm{mg} / \mathrm{kg} n=8$; CDP571 $n=5$ mice and mouse: PBS $n=3$; vehicle $n=8$; UCB-9260 $10 \mathrm{mg} / \mathrm{kg} n=7,30 \mathrm{mg} / \mathrm{kg} n=6$, 100 and $300 \mathrm{mg} / \mathrm{kg} n=8$; CDP571 $n=5$ mice, from Charles River UK) were dosed orally with vehicle ( $1 \%$ methylcellulose, $400 \mathrm{cps})$ or compound, $30 \mathrm{~min}$ prior to intraperitoneal administration of mouse $(0.05 \mu \mathrm{g} / \mathrm{kg})$ or human $(0.03$ or $1 \mu \mathrm{g} / \mathrm{kg})$ TNF diluted in PBS. Anti-TNFa biologics, CDP571 21 (10 mg/kg) and etanercept $(30 \mathrm{mg} / \mathrm{kg})$, diluted in PBS, were dosed intravenously prior to human and mouse TNF challenge. Two hours after the TNF challenge, mice were sacrificed and the peritoneal cavity lavaged with $3 \mathrm{~mL}$ of FACS buffer. An aliquot $(0.3 \mathrm{~mL})$ of lavage fluid was used to assess the number $\mathrm{CD} 45^{+} \mathrm{GR} 1{ }^{+}$cells by flow cytometry. Briefly, the cells were treated with ACK lysis buffer, washed and suspended in FACS buffer prior to staining with FITC anti-mouse CD45 and PE anti-mouse GR1. Data are shown as mean \pm standard error of the number of CD $45^{+}$GR $-1^{+}$cells. Statistical significance $\left({ }^{*} p<0.05,{ }^{* *} p<0.01,{ }^{* * * *} p<0.0001\right)$ was determined using one-way ANOVA with Dunnett's multiple comparison test.
Collagen antibody induced arthritis model. Adult male Balb/c mice (aged 6-8 weeks, vehicle $n=8$; UCB-9260 $n=8$ and AB501 $n=6$ mice, from Charles River UK) received $4 \mathrm{mg}$ of anti-collagen type II antibody cocktail intraperitoneally, which was followed $24 \mathrm{~h}$ later with $25 \mu \mathrm{g}$ of lipopolysaccharide (LPS) intraperitoneally. Dosing with vehicle (30\% cyclodextrin po bid) or UCB-9260 (150 mg/kg po bid) was initiated $6 \mathrm{~h}$ post-LPS administration. Ab501 (in-house anti-mouse TNF antibody, $100 \mathrm{~m} / \mathrm{kg}$ ) was administered intravenously $6 \mathrm{~h}$ post-LPS administration followed by three further doses administered subcutaneously at $48-\mathrm{h}$ intervals. Animals were scored for signs of arthritis and weighed daily. The following scoring system was used for signs of arthritis: 0-no arthritis, 1-wrist/ankle affected, 2-wrist/ankle and pad affected and 3-wrist/ankle, pad, and digits affected. Data shown as the mean \pm standard error of arthritis clinical score for the treatment group. Statistical significance $\left({ }^{*} p<0.05,{ }^{* *} p<0.01\right)$ was determined using one-way ANOVA with Dunnett's multiple comparison test.

All in vivo studies were reviewed by an internal ethical review body and conducted in accordance with the Animals (Scientific Procedures) Act 1986, EU Directive 2010/63/EU. Animals were kept under a light/dark cycle of $12 / 12 \mathrm{~h}$ and had access to food and water ad libitum.

Zymosan induced neutrophil recruitment in vivo. Adult male $\mathrm{Balb} / \mathrm{c}$ mice (aged 6-8 weeks, PBS $n=5$; vehicle $n=8$; UCB-9260 10, 30, 100 and $300 \mathrm{mg} / \mathrm{kg} n=8$; Ab501 $n=3$ mice, from Charles River UK) were dosed intravenously with $30 \mathrm{mg} /$ $\mathrm{kg}$ of Ab501 (in-house anti-mouse TNF antibody) diluted in PBS $1 \mathrm{~h}$ prior to zymosan challenge. Vehicle (30\% cyclodextrin) or UCB-9260 at 10, 30, 100 and $300 \mathrm{mg} / \mathrm{kg}$ was dosed orally at the time of zymosan challenge. Zymosan (R\&D Systems) was administered by intraperitoneal injection at a concentration of $1 \mu \mathrm{g}$ per mouse in PBS $(100 \mu \mathrm{L})$. One hour post oral administration of UCB-9260, mice were bled via the tail to analyse exposure levels of the compound. Four hours after the zymosan challenge, mice were sacrificed and the peritoneal cavity lavaged with $3 \mathrm{~mL}$ of FACS buffer. An aliquot $(0.3 \mathrm{~mL})$ of lavage fluid was used to assess the number of $\mathrm{CD} 45^{+} \mathrm{GR} 1^{+}$cells by flow cytometry. Briefly, the cells were treated with ACK lysis buffer, washed and suspended in FACS buffer prior to staining with FITC anti-mouse CD45 and PE anti-mouse GR1 (BD Biosciences). Data are shown as mean \pm standard error of the number of CD $45^{+}$GR-1 $1^{+}$cells. Statistical significance $\left({ }^{*} p<0.05,{ }^{* *} p<0.01,{ }^{* *} p<0.001\right.$ and $\left.{ }^{* * * *} p<0.0001\right)$ was determined using one-way ANOVA with Dunnett's multiple comparison test.

Reporting summary. Further information on research design is available in the Nature Research Reporting Summary linked to this article.

\section{Data availability}

The data supporting this study are available from the corresponding author upon resoanable request. The structural data have been deposited with the Protein Data Bank under accession codes 6OOY for UCB-6876, 6OOZ for UCB-5307, and 6OP0 for UCB9260. NMR spectral data are available for UCB-5307 (Supplementary Figs. 13, 14) and for UCB-9260 (Supplementary Figs. 16, 17). High resolution mass spectrometry (HRMS) is also available for UCB-5307 (Supplementary Fig. 15) and UCB-9260 (Supplementary Fig. 18). The source data underlying Figs. 4 and 6, Supplementary Figs. 6-9 and 12, and Supplementary Tables 4-6 are provided in the source data files.

Received: 10 April 2019; Accepted: 14 November 2019; Published online: 19 December 2019

\section{References}

1. Willrich, M. A., Murray, D. L. \& Snyder, M. R. Tumor necrosis factor inhibitors: clinical utility in autoimmune diseases. Transl. Res. 165, 270-282 (2015).

2. Murdaca, G. et al. Immunogenicity of infliximab and adalimumab: what is its role in hypersensitivity and modulation of therapeutic efficacy and safety? Expert Opin. Drug Saf. 15, 43-52 (2016)

3. Rees, H. Supply Chain Management in the Drug Industry: Delivering Patient Value for Pharmaceuticals and Biologics. (John Wiley \& Sons, 2011).

4. He, M. M. et al. Small-molecule inhibition of TNF-alpha. Science 310, 1022-1025 (2005).

5. Alexiou, P. et al. Rationally designed less toxic SPD-304 analogs and preliminary evaluation of their TNF inhibitory effects. Arch. der Pharmazie 347, 798-805 (2014).

6. Luzi, S. et al. Subunit disassembly and inhibition of TNFalpha by a semisynthetic bicyclic peptide. Protein Eng. Des. Selection 28, 45-52 (2015)

7. Papaneophytou, C. et al. Synthesis and biological evaluation of potential small molecule inhibitors of tumor necrosis factor. MedChemComm 6, 1196-1209 (2015)

8. Blevitt, J. M. et al. Structural basis of small-molecule aggregate induced inhibition of a protein-protein interaction. J. medicinal Chem. 60, 3511-3517 (2017). 
9. McGovern, S. L., Caselli, E., Grigorieff, N. \& Shoichet, B. K. A common mechanism underlying promiscuous inhibitors from virtual and highthroughput screening. J. Medicinal Chem. 45, 1712-1722 (2002).

10. $\mathrm{Hu}, \mathrm{Z}$. et al. Japonicone A antagonizes the activity of TNF-alpha by directly targeting this cytokine and selectively disrupting its interaction with TNF receptor-1. Biochem. Pharmacol. 84, 1482-1491 (2012).

11. Murali, R. et al. Disabling TNF receptor signaling by induced conformational perturbation of tryptophan-107. Proc. Natl Acad. Sci. USA 102, 10970-10975 (2005).

12. Lo, C. H. et al. Noncompetitive Inhibitors TNFR1 Probe Conformational Activation S. 12, eaav5637 (2019)

13. Davis, J. M. \& Colangelo, J. Small-molecule inhibitors of the interaction between TNF and TNFR. Future Medicinal Chem. 5, 69-79 (2013).

14. Richmond, V., Michelini, F. M., Bueno, C. A., Alche, L. E. \& Ramirez, J. A Small Molecules as Anti-TNF Drugs. Curr. Medicinal Chem. 22, 2920-2942 (2015).

15. Arkin, M. R. \& Wells, J. A. Small-molecule inhibitors of protein-protein interactions: progressing towards the dream. Nat. Rev. Drug Discov. 3, 301-317 (2004).

16. Gurung, A. B., Bhattacharjee, A., Ajmal Ali, M., Al-Hemaid, F. \& Lee, J. Binding of small molecules at interface of protein-protein complex-A newer approach to rational drug design. Saudi J. Biol. Sci. 24, 379-388 (2017).

17. Fischer, G., Rossmann, M. \& Hyvonen, M. Alternative modulation of proteinprotein interactions by small molecules. Curr. Opin. Biotechnol. 35, 78-85 (2015).

18. Bartlett, P. A. \& Marlowe, C. K. Possible role for water dissociation in the slow binding of phosphorus-containing transition-state-analogue inhibitors of thermolysin. Biochemistry 26, 8553-8561 (1987).

19. Barducci, A., Bussi, G. \& Parrinello, M. Well-tempered metadynamics: a smoothly converging and tunable free-energy method. Phys. Rev. Lett. 100, 020603 (2008)

20. Carrington, B., Myers, W. K., Horanyi, P., Calmiano, M. \& Lawson, A. D. G. Natural conformational sampling of human tnfalpha visualized by double electron-electron resonance. Biophysical J. 113, 371-380 (2017)

21. van Schie, K. A. et al. Therapeutic TNF inhibitors can differentially stabilize trimeric TNF by inhibiting monomer exchange. Sci. Rep. 6, 32747 (2016).

22. Ameloot, P., Declercq, W., Fiers, W., Vandenabeele, P. \& Brouckaert, P. Heterotrimers formed by tumor necrosis factors of different species or muteins. J. Biol. Chem. 276, 27098-27103 (2001).

23. Steed, P. M. et al. Inactivation of TNF signaling by rationally designed dominant-negative TNF variants. Science 301, 1895-1898 (2003).

24. Cabal-Hierro, L. \& Lazo, P. S. Signal transduction by tumor necrosis factor receptors. Cell. Signal. 24, 1297-1305 (2012).

25. Hayden, M. S. \& Ghosh, S. Regulation of NF-kappaB by TNF family cytokines. Semin. Immunol. 26, 253-266 (2014).

26. Nesbitt, A. et al. Mechanism of action of certolizumab pegol (CDP870): in vitro comparison with other anti-tumor necrosis factor alpha agents. Inflamm. Bowel Dis. 13, 1323-1332 (2007).

27. Sayers, T. J. et al. Effect of cytokines on polymorphonuclear neutrophil infiltration in the mouse. Prostaglandin- and leukotriene-independent induction of infiltration by IL-1 and tumor necrosis factor. J. Immunol. 141, 1670-1677 (1988).

28. Lewis, M. et al. Cloning and expression of cDNAs for two distinct murine tumor necrosis factor receptors demonstrate one receptor is species specific. Proc. Natl Acad. Sci. USA 88, 2830-2834 (1991).

29. Stephens, S. et al. Comprehensive pharmacokinetics of a humanized antibody and analysis of residual anti-idiotypic responses. Immunology 85, 668-674 (1995).

30. Terato, K. et al. Collagen-induced arthritis in mice: synergistic effect of E. coli lipopolysaccharide bypasses epitope specificity in the induction of arthritis with monoclonal antibodies to type II collagen. Autoimmunity 22, 137-147 (1995).

31. Wells, J. A. \& McClendon, C. L. Reaching for high-hanging fruit in drug discovery at protein-protein interfaces. Nature 450, 1001-1009 (2007).

32. Hubbard, R. E. in Fragment-Based Drug Discovery Ch. 6. 126-152 (The Royal Society of Chemistry, 2015).

33. Clackson, T. \& Wells, J. A. A hot spot of binding energy in a hormonereceptor interface. Science 267, 383-386 (1995).

34. Silvian, L. F. et al. Small molecule inhibition of the TNF family cytokine CD40 ligand through a subunit fracture mechanism. ACS Chem. Biol. 6, 636-647 (2011).

35. Thiel, P., Kaiser, M. \& Ottmann, C. Small-molecule stabilization of protein protein interactions: an underestimated concept in drug discovery? Angew. Chem. 51, 2012-2018 (2012).

36. Lawson, A. D. Antibody-enabled small-molecule drug discovery. Nat. Rev. Drug Discov. 11, 519-525 (2012)

37. Kabsch, W. XDS. Acta Crystallogr. 66, 125-132 (2010).

38. Emsley, P., Lohkamp, B., Scott, W. G. \& Cowtan, K. Features and development of Coot. Acta Crystallogr. 66, 486-501 (2010).
39. Murshudov, G. N., Vagin, A. A. \& Dodson, E. J. Refinement of macromolecular structures by the maximum-likelihood method. Acta Crystallogr. 53, 240-255 (1997).

40. Chen, V. B. et al. MolProbity: all-atom structure validation for macromolecular crystallography. Acta Crystallogr. 66, 12-21 (2010).

41. Berman, H., Henrick, K. \& Nakamura, H. Announcing the worldwide Protein Data Bank. Nat. Struct. Biol. 10, 980 (2003)

42. Berman, H. M. et al. The Protein Data Bank. Nucleic Acids Res. 28, 235-242 (2000).

43. Choi, Y. \& Deane, C. M. FREAD revisited: accurate loop structure prediction using a database search algorithm. Proteins 78, 1431-1440 (2010).

44. Consortium, U. Reorganizing the protein space at the Universal Protein Resource (UniProt). Nucleic Acids Res. 40, D71-D75 (2012).

45. Hornak, V. et al. Comparison of multiple Amber force fields and development of improved protein backbone parameters. Proteins 65, 712-725 (2006).

46. Case, D. et al. AMBER11 and AmberTools version 1.5. (2010).

47. Jorgensen, W. L. J. Revised TIPS for simulations of liquid water and aqueous solutions. J. Chem. Phys. 77, 4156-4163 (1982).

48. Phillips, J. C. et al. Scalable molecular dynamics with NAMD. J. Comput. Chem. 26, 1781-1802 (2005).

49. Harvey, M. J., Giupponi, G. \& Fabritiis, G. D. ACEMD: accelerating biomolecular dynamics in the microsecond time scale. J. Chem. Theory Comput. 5, 1632-1639 (2009).

50. Bonomi, M. et al. PLUMED: a portable plugin for free-energy calculations with molecular dynamics. Comput. Phys. Commun. 180, 1961-1972 (2009).

51. Darden, T., Perera, L., Li, L. \& Pedersen, L. New tricks for modelers from the crystallography toolkit: the particle mesh Ewald algorithm and its use in nucleic acid simulations. Structure 7, R55-R60 (1999).

52. Crespo, Y., Marinelli, F., Pietrucci, F. \& Laio, A. Metadynamics convergence law in a multidimensional system. Phys. Rev. E 81, 055701 (2010).

53. Van Der Spoel, D. et al. GROMACS: fast, flexible, and free. J. Comput. Chem. 26, 1701-1718 (2005)

\section{Acknowledgements}

The authors wish to thank David Schubert for providing cell-signalling data and acknowledge the significant contribution of Mark Merriman and Andrew Nesbitt for cell assays. They also thank: Jeff Kennedy, Ian Fahy, Andrew Gill and Oliver Zaccheo for providing Biacore screening data, James Heads for providing Thermofluor data, Gill Watt for preparation of the in vivo section, Anne Foley for the synthesis of UCB-9260, and personnel at UCB Pharma in Seattle and Boston for their contribution to the research and paper. Special contributions include Tom Edwards, David Dranow, Jim Fairman and Doug Davies for review of structures determined, Kateri Atkins for execution of analytic size exclusion chromatography experiments, Oliver Durrant for providing Dynamic Light Scattering data to characterise the compounds, Graham Warrellow for his role in initiating this project, Alistair Henry and Luis Castro for helpful discussions, and Sanofi for its generous support. Finally, the authors would also like to acknowledge Sarah Hibbert, $\mathrm{PhD}$, of iMed Comms, Macclesfield, UK, an Ashfield Company, part of UDG Healthcare plc, for editing support that was funded by UCB Pharma in accordance with Good Publications Practice (GPP3) guidelines (http://www.ismpp.org/gpp3), and Linda Feighery, PhD, CMPP, of UCB Pharma for publication and editorial support.

\section{Author contributions}

J.O'C., J.P., B.K., T.N., S.R., R.D., T.A., A.B., F.L., A.M., A.V., B.C. D.F. and B.Co. were all involved in experimental design. J.O'C., J.P., B.K., T.N., S.R., R.D., D.McM., D.F., T.A., A.B., F.L., A.M., A.V., B.C., B.Co., T.C., T.B. and A.L. all contributed to data collection and/or interpretation. All authors were involved in the writing the paper and final approval of the content.

\section{Competing interests}

J.O.'C., J.P., B.K., T.N., S.R., R.D., D.McM., D.F., T.C., F.L., A.M., A.V., B.C., B.Co., T.B. and A.L. are/were all employees of UCB Pharma and may hold stock and/or stock options. T.A. and A.B. declare no competing interests.

\section{Additional information}

Supplementary information is available for this paper at https://doi.org/10.1038/s41467 019-13616-1.

Correspondence and requests for materials should be addressed to J.O.'C.

Peer review information Nature Communications thanks the anonymous reviewers for their contribution to the peer review of this work. Peer reviewer reports are available.

Reprints and permission information is available at http://www.nature.com/reprints

Publisher's note Springer Nature remains neutral with regard to jurisdictional claims in published maps and institutional affiliations. 
(c) (i) Open Access This article is licensed under a Creative Commons Attribution 4.0 International License, which permits use, sharing, adaptation, distribution and reproduction in any medium or format, as long as you give appropriate credit to the original author(s) and the source, provide a link to the Creative Commons license, and indicate if changes were made. The images or other third party material in this article are included in the article's Creative Commons license, unless indicated otherwise in a credit line to the material. If material is not included in the article's Creative Commons license and your intended use is not permitted by statutory regulation or exceeds the permitted use, you will need to obtain permission directly from the copyright holder. To view a copy of this license, visit http://creativecommons.org/ licenses/by/4.0/.

(C) The Author(s) 2019 